\title{
Evaluation of Antibacterial Activity of Some Traditionally Used Medicinal Plants against Human Pathogenic Bacteria
}

\author{
Bishnu P. Marasini,, ${ }^{1,2}$ Pankaj Baral,,3 Pratibha Aryal, ${ }^{4}$ \\ Kashi R. Ghimire, ${ }^{1}$ Sanjiv Neupane, ${ }^{1}$ Nabaraj Dahal, ${ }^{5}$ Anjana Singh, ${ }^{1}$ \\ Laxman Ghimire, ${ }^{3}$ and Kanti Shrestha ${ }^{2}$ \\ ${ }^{1}$ Central Department of Microbiology, Tribhuvan University, Kirtipur, Kathmandu, Nepal \\ ${ }^{2}$ Nepal Academy of Science and Technology (NAST), Khumaltar, Lalitpur, Nepal \\ ${ }^{3}$ Department of Pathobiological Science, School of Veterinary Medicine, Louisiana State University, Baton Rouge, LA 70803, USA \\ ${ }^{4}$ Department of Biochemistry, Faculty of Medicine Siriraj Hospital, Mahidol University, Bangkok 10700, Thailand \\ ${ }^{5}$ Patan Hospital, Patan, Lalitpur, Nepal
}

Correspondence should be addressed to Pankaj Baral; pbaral@lsu.edu and Kanti Shrestha; kantishrestha2006@gmail.com

Received 22 October 2014; Accepted 16 January 2015

Academic Editor: Frederick D. Quinn

\begin{abstract}
Copyright (C) 2015 Bishnu P. Marasini et al. This is an open access article distributed under the Creative Commons Attribution License, which permits unrestricted use, distribution, and reproduction in any medium, provided the original work is properly cited.

The worldwide increase of multidrug resistance in both community- and health-care associated bacterial infections has impaired the current antimicrobial therapy, warranting the search for other alternatives. We aimed to find the in vitro antibacterial activity of ethanolic extracts of 16 different traditionally used medicinal plants of Nepal against 13 clinical and 2 reference bacterial species using microbroth dilution method. The evaluated plants species were found to exert a range of in vitro growth inhibitory action against the tested bacterial species, and Cynodon dactylon was found to exhibit moderate inhibitory action against 13 bacterial species including methicillin-resistant Staphylococcus aureus, imipenem-resistant Pseudomonas aeruginosa, multidrug-resistant Salmonella typhi, and S. typhimurium. The minimum inhibitory concentration (MIC) values of tested ethanolic extracts were found from 31 to $>25,000 \mu \mathrm{g} / \mathrm{mL}$. Notably, ethanolic extracts of Cinnamomum camphora, Curculigo orchioides, and Curcuma longa exhibited the highest antibacterial activity against $S$. pyogenes with a MIC of 49, 49, and $195 \mu \mathrm{g} / \mathrm{mL}$, respectively; whereas chloroform fraction of Cynodon dactylon exhibited best antibacterial activity against S. aureus with a MIC of $31 \mu \mathrm{g} / \mathrm{mL}$. Among all, C. dactylon, C. camphora, C. orchioides, and C. longa plant extracts displayed a potential antibacterial activity of MIC $<100 \mu \mathrm{g} / \mathrm{mL}$.
\end{abstract}

\section{Introduction}

The emergence and spread of multidrug-resistant (MDR) bacterial pathogens have substantially threatened the current antibacterial therapy [1]. MDR bacterial infections often lead to increased mortality, longer length of stays in hospitals, and higher cost of treatment and care $[1,2]$. The most problematic bacteria include, but are not limited to, extended-spectrum $\beta$-lactamase-producing Escherichia coli (ESBL-EC) and Klebsiella pneumoniae (ESBL-KP), carbapenem-resistant Enterobacteriaceae, Pseudomonas aeruginosa, and Acinetobacter baumannii, hospital-acquired methicillin-resistant Staphylococcus aureus (MRSA), and vancomycin resistant Enterococcus (VRE) [2-4]. Thus, Infectious Diseases Society of
America has recognized MRSA, VRE, ESBL-EP, ESBL-KP, and Pseudomonas aeruginosa as notorious pathogens among the six major pathogens to which therapies with effective newer antimicrobials are urgently required $[1,4]$.

The therapeutic options for these pathogens are extremely limited and physicians are forced to use expensive or previously discarded drugs, such as colistin, that are associated with significant side effect to the patients' health [1]. Therefore, it is necessary to search the other alternatives that can potentially be effective in the treatment of these problematic bacterial infections. The usefulness of plant extracts for antimicrobial therapy and/or other diseases have been observed to be promising remedies since ancient time in Chinese medicine, Ayurveda, Arabic, and Unani medicine 
[5]. The inclusion of traditionally used medicines including phytomedicine, if they prove safe and effective, into national health care system is suggested by World Health Organization [5]. Although a large number of medicinal plants $(>500$ plants) have been reported to be used by Nepalese people since a long time for primary health care, there has been a paucity in data regarding their in vitro or in vivo efficacy [6]. In this study, we aimed to determine the in vitro antibacterial activity of extracts from some selected medicinal plants from Nepal against the most common bacterial pathogens including MDR bacteria. The sixteen selected plants in this study have remained as integral part of traditional medicine in Nepal to treat different types of infectious diseases, including diarrhea, respiratory tract infection, cholera, and skin and wound infections (Table 1).

\section{Materials and Methods}

2.1. Plant Materials and Extract Preparation. Popular plants used in traditional medicine by the Nepalese people across the country, based upon previous ethnobotanical literatures and potential medicinal values as judged by local healers, were screened and selected to include in the present study. The collected plants were identified at the National Herbarium and Plant Laboratories, Kathmandu, and the voucher specimens have been deposited at National Academy of Science and Technology, Nepal. The most potential parts of the plants that could exhibit antimicrobial activity as judged by the traditional trend for the parts to be used for the treatment of diseases were selected for the study (Table 1). All collected plant materials were air-dried at room temperature under shade, and pulverized into fine powder and processed for extract isolation. The elaborated steps for the isolation and processing of the plant materials are covered in supplementary information (details are in Supplementary Material available online at http://dx.doi.org/10.1155/2015/265425).

\subsection{Antimicrobial Testing}

2.2.1. Bacteria. A total of 15 bacterial species were used in the study, which includes ten Gram-negative bacteria (clinical strains: ESBL-EC, Citrobacter freundii, Enterobacter cloacae, ESBL-KP, imipenem-resistant $P$. aeruginosa, S. enteritidis, MDR S. typhi, S. typhimurium, and Vibrio cholerae and a reference strain E. coli ATCC 25922) and five Gram-positive bacteria (clinical strains: MRSA, Enterococcus faecalis, Streptococcus agalactiae, and $S$. pyogenes and a reference stain $S$. aureus ATCC 25923). All of the tested bacteria were identified and characterized by culturing in the specific appropriate media followed by the rapid testing (Gram's stain, catalase, oxidase, coagulase, and bile solubility) and the biochemical testing (IMViC (Indole, methyl red, VogesProskauer, and citrate), TSI (triple sugar iron), O/F (oxidation/fermentation), urease, and nitrate reduction). Antimicrobial susceptibility was performed for all tested clinical bacterial strains by disk diffusion method following Clinical and Laboratory Standards Institute (CLSI) recommendations
[7]. For the characterization of MDR bacteria, a recently standardized definition for MDR by European Centre for Disease Prevention and Control (ECDC) and Centers for Disease Control and Prevention (CDC) was followed; accordingly MDR was defined as acquired nonsusceptibility to at least one agent in three or more antimicrobial categories [3]. The antibiotic resistance pattern of tested bacteria is shown in Supplemental Table 1.

2.3. Standardization of Bacterial Suspension. The bacterial suspensions were standardized following the CLSI guidelines for aerobic bacteria [8]. All of the tested bacteria were grown in Mueller Hinton Broth (MHB, Hi-Media) for 18$24 \mathrm{~h}$, followed by the matching of bacterial suspension to the turbidity equivalent to $0.5 \mathrm{McFarland}$ solution $(1-2 \times$ $10^{8} \mathrm{CFU} / \mathrm{mL}$ ) with the addition of sterile saline.

2.4. Minimum Inhibitory Concentration (MIC) Determination. Antibacterial activities of the extracts were first screened by agar-well diffusion method as described previously [9]. The MIC testing was performed for all the plant extracts that were judged as active (inhibition zone $>7 \mathrm{~mm}$ ) against at least one test organism by agar-well diffusion method. The MIC values were determined by microbroth dilution method using 96-well plates (detailed procedure is in Supplementary Material).

\section{Results and Discussion}

A total of 16 ethanolic extracts from 16 nonrepetitive plants were tested for antibacterial activity qualitatively as well as quantitatively against the 13 clinical bacterial species and the 2 reference bacterial species. The MDR and non-MDR clinical strains used in this work were isolated from human infections diagnosed in a tertiary care hospital of Nepal (Supplemental Table 1). Although some extracts exhibited a good antibacterial activity towards different tested bacterial isolates, many plant extracts exhibited a limited antibacterial activity against the test bacterial isolates as judged by their higher MIC values (Table 2). However, these extracts showed the larger inhibition zone (by agar-well diffusion method, Supplemental Table 2) as well as low MIC values (Table 2) against the Gram-positive bacteria when compared against the Gram-negative bacteria. Our results are in agreement with several previous findings demonstrating greater activity of the plant extracts towards Gram-positive bacteria compared to Gram-negative bacteria $[10,11]$. One of the most plausible reasons behind such observation, as also mentioned by others, is the different nature of cell wall among Grampositive and Gram-negative bacteria [11]; however efflux pump system of Gram-negative bacteria may mediate for such difference [12].

The strongest antibacterial activity $(\mathrm{MIC}=49 \mu \mathrm{g} / \mathrm{mL})$ was observed for the extracts from Curculigo orchioides and Cinnamomum camphora against $S$. pyogenes, followed by Curcuma longa extract against E. faecalis (MIC $=98 \mu \mathrm{g} / \mathrm{mL})$ (Table 2), establishing the traditional values of the use of these plants for the remedies of bronchitis, and skin and/or wound 


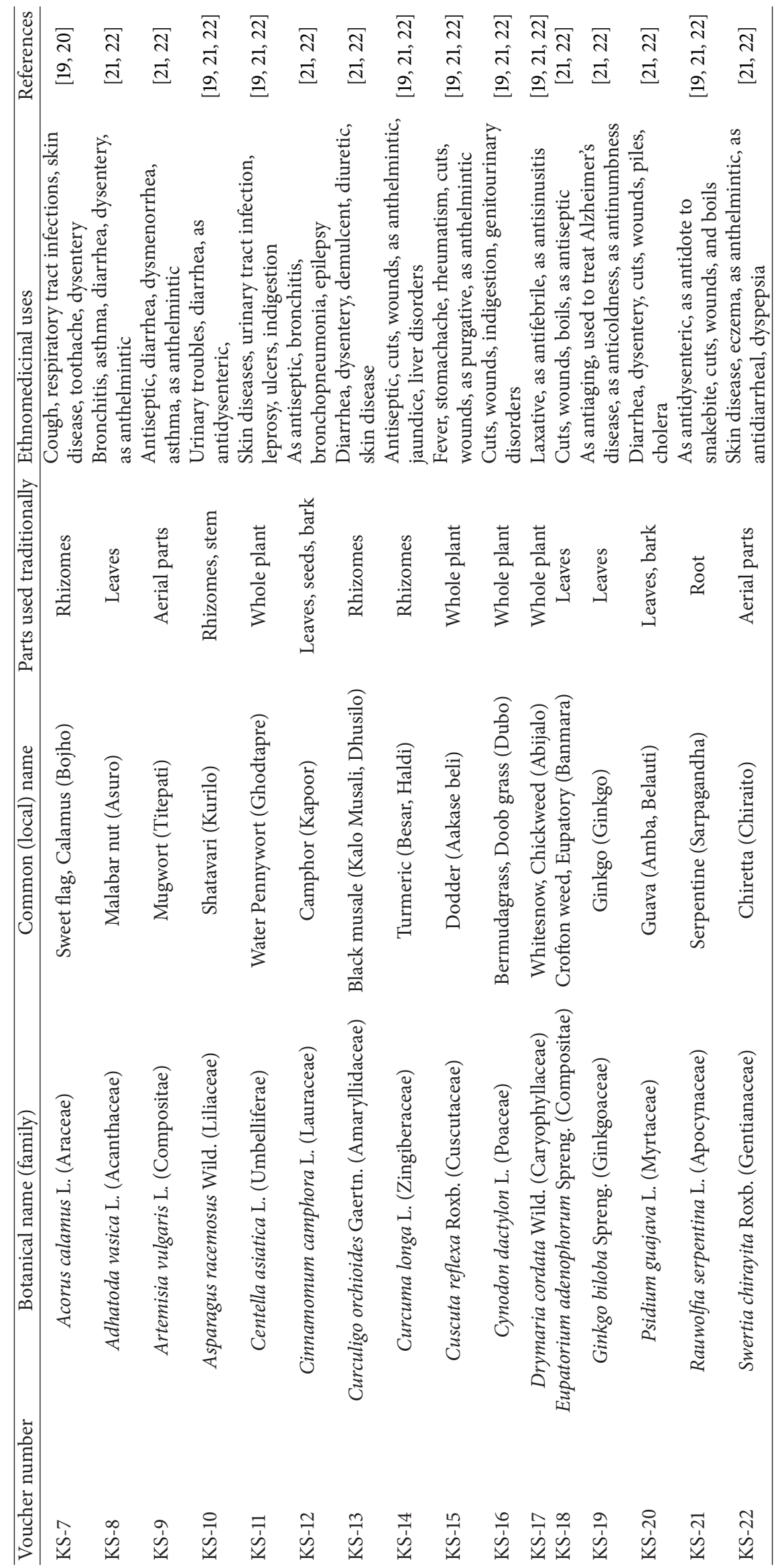




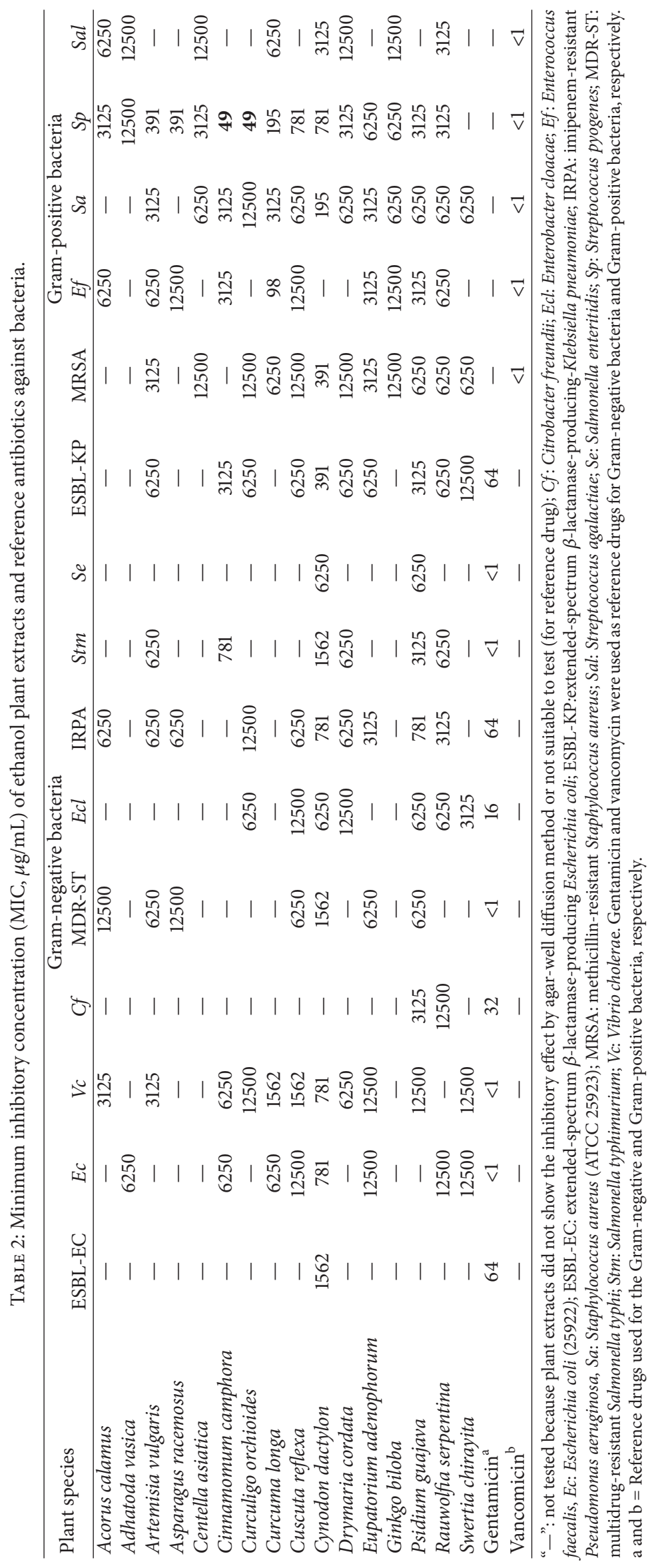


TABLE 3: MIC $(\mu \mathrm{g} / \mathrm{mL})$ of subfraction of ethanol extracts of Cynodon dactylon and reference antibiotics against bacteria.

\begin{tabular}{|c|c|c|c|c|c|c|c|c|c|c|c|c|c|c|c|}
\hline \multirow{2}{*}{ Solvent system } & \multicolumn{10}{|c|}{ Gram-negative bacteria } & \multicolumn{5}{|c|}{ Gram-positive bacteria } \\
\hline & ESBL-EC & $E c$ & $V c$ & $C f$ & MDR-ST & $\mathrm{Ecl}$ & IRPA & Stm & Se & ESBL-KP & MRSA & $E f$ & $\mathrm{Sa}$ & $S p$ & Sal \\
\hline n-Hexane & - & - & - & - & - & - & - & 500 & - & - & - & - & - & - & - \\
\hline Chloroform & 250 & 63 & - & - & - & 125 & - & 500 & - & - & 63 & - & 31 & - & - \\
\hline n-Butanol & - & - & - & - & - & - & - & - & - & 250 & 125 & 500 & 63 & - & - \\
\hline Water & - & - & 500 & - & - & - & - & - & - & - & - & - & - & - & - \\
\hline Gentamicin $^{\mathrm{a}}$ & 64 & $<1$ & $<1$ & 32 & $<1$ & 16 & 64 & $<1$ & $<1$ & 64 & - & - & - & - & - \\
\hline Vancomicin $^{\mathrm{b}}$ & - & - & - & - & - & - & - & - & - & - & $<1$ & $<1$ & $<1$ & $<1$ & $<1$ \\
\hline
\end{tabular}

"-": not tested because plant extracts did not show the inhibitory effect by agar-well diffusion method or not suitable to test (for reference drug); $C f:$ Citrobacter freundii; Ecl: Enterobacter cloacae; Ef: Enterococcus faecalis; Ec: Escherichia coli (25922); ESBL-EC: extended-spectrum $\beta$-lactamase-producing Escherichia coli; ESBL-KP: extended-spectrum $\beta$-lactamase-producing-Klebsiella pneumoniae; IRPA: imipenem-resistant Pseudomonas aeruginosa; Sa: Staphylococcus aureus (ATCC 25923); MRSA: methicillin-resistant Staphylococcus aureus; Sal: Streptococcus agalactiae; Se: Salmonella enteritidis; Sp: Streptococcus pyogenes; MDRST: multidrug-resistant Salmonella typhi; Stm: Salmonella typhimurium; Vc: Vibrio cholerae; a and b: gentamicin and vancomycin were used as reference drugs for Gram-negative bacteria and Gram-positive bacteria, respectively.

infections. C. dactylon extract showed a broad-spectrum antibacterial activity compared to other extracts inhibiting 12 bacterial species including MDR-ST, ESBL-EC, ESBL-KP, and MRSA with MIC values ranging from 391 to $3125 \mu \mathrm{g} / \mathrm{mL}$ (Table 2). Therefore, ethanolic extractof $C$. dactylon fractionated into different solvents to evaluate its antibacterial property and chloroform fraction exhibited good inhibitory effect with MIC values ranging from 31 to $250 \mu \mathrm{g} / \mathrm{mL}$ (Table 3). The minimum bactericidal concentration (MBC) values of the plant extracts against tested bacterial species were also found largely higher and ranged from 98 to $>25,000 \mu \mathrm{g} / \mathrm{mL}$ (Supplemental Table 3). The observed MIC and MBC values of the plant extracts in this study are in a range or lower than the values of other plant extracts reported from different countries [13-15], but are higher than those values that have been reported in a number of reports [11, 16, 17]. The high temperature during soxhlet extraction in our study might be responsible for the degradation of antibacterial active ingredients.

In our study, the plant extracts from C. longa, G. biloba, and $R$. serpentina were demonstrated to inhibit the growth of all tested Gram-positive bacteria, whereas only the plant extract from C. dactylon was observed to inhibit the growth of all tested Gram-negative bacteria except C. freundii (Table 2 and Supplemental Table 2). Recent studies on antimicrobial effect of $C$. dactylon had shown that it is also effective against some other bacteria, such as Bacillus subtilis and Aeromonas hydrophila [18]. Although certain number of extracts exhibited good antibacterial potency, in contrary to our expectation, a limited antibacterial potency of some plants suggest that there is no complete agreement between the traditional use of medicinal plants in the crude form for the remedy of infectious diseases. Further study, however, is still warranted to explore their effectiveness to inhibit the growth of parasites, viruses, and/or fungi. Another possibility for the limited antibacterial potency of some plants may be due to soxhlet extraction method and use of crude extracts. Instead of it, percolation extraction, subfraction, semipure compound, or pure compounds isolated from these plants might exhibit better antibacterial activity. Although we have shown the potent in vitro activity of few traditional plant extracts (e.g., C. camphora, C. orchioides, and C. longa) for certain bacteria, we are not certain about if such activity will be translated in vivo. Future epidemiological studies are necessary to understand the effectiveness/impact of use of extracts from such medicinal plants in population.

\section{Conclusion}

In this study we evaluated the antibacterial activity of 16 commonly used traditional medicinal plants from Nepal. Some extracts displayed a potent antibacterial activity with MIC $<100 \mu \mathrm{g} / \mathrm{mL}$, indicating that these plants could be a good source for the antibacterials to combat MDR bacterial infections. Further studies are necessary for these potent plant extracts to evaluate the other parameters of antimicrobial efficacy (e.g., in vivo efficacy, toxicity, and antimycobacterial, antiviral, and antiparasitic activity).

\section{Conflict of Interests}

The authors declare that there is no conflict of interests.

\section{Acknowledgments}

The authors would like to thank Mr. Puran Prasad Kurmi, National Herbarium and Plant Laboratories, Kathmandu, for helping them in identification of plants. They are thankful to the staff of Nepal Academy of Science and Technology (NAST), Lalitpur, Nepal, for their cooperation during the study.

\section{References}

[1] H. W. Boucher, G. H. Talbot, J. S. Bradley et al., "Bad bugs, no drugs: no ESKAPE! An update from the Infectious Diseases Society of America," Clinical Infectious Diseases, vol. 48, no. 1, pp. 1-12, 2009.

[2] H. Giamarellou, "Multidrug-resistant Gram-negative bacteria: how to treat and for how long," International Journal of Antimicrobial Agents, vol. 36, Supplement 2, pp. S50-S54, 2010. 
[3] A.-P. Magiorakos, A. Srinivasan, R. B. Carey et al., "Multidrugresistant, extensively drug-resistant and pandrug-resistant bacteria: an international expert proposal for interim standard definitions for acquired resistance," Clinical Microbiology and Infection, vol. 18, no. 3, pp. 268-281, 2012.

[4] G. H. Talbot, J. Bradley, J. E. Edwards Jr., D. Gilbert, M. Scheid, and J. G. Bartlett, "Bad bugs need drugs: an update on the development pipeline from the Antimicrobial Availability Task Force of the Infectious Diseases Society of America," Clinical Infectious Diseases, vol. 42, no. 5, pp. 657-668, 2006.

[5] World Health Organization, WHO Traditional Medicine Strategy 2002-2005, World Health Organization, Geneva, Switzerland, 2002.

[6] R. M. Kunwar and R. W. Bussmann, "Ethnobotany in the Nepal Himalaya," Journal of Ethnobiology and Ethnomedicine, vol. 4, article 24, 2008.

[7] CLSI, Performance Standards for Antimicrobial Susceptibility Testing; Seventeenth Informational Supplement, CLSI Document M100-S17, Clinical and Laboratory Standards Institute, Wayne, $\mathrm{Pa}$, USA, 2007.

[8] CLSI, "Methods for dilution antimicrobial susceptibility tests for bacteria that grows aerobically, approved standard-ninth edition," CLSI Document MO7-A9, Clinical and Laboratory Standards Institute, Wayne, Pa, USA, 2012.

[9] C. Pérez and C. Anesini, "In vitro antibacterial activity of Argentine folk medicinal plants against Salmonella typhi," Journal of Ethnopharmacology, vol. 44, no. 1, pp. 41-46, 1994.

[10] R. Valsaraj, P. Pushpangadan, U. W. Smitt, A. Adsersen, and U. Nyman, "Antimicrobial screening of selected medicinal plants from India," Journal of Ethnopharmacology, vol. 58, no. 2, pp. 75-83, 1997.

[11] I. C. Zampini, S. Cuello, M. R. Alberto et al., "Antimicrobial activity of selected plant species from 'the Argentine Puna' against sensitive and multi-resistant bacteria," Journal of Ethnopharmacology, vol. 124, no. 3, pp. 499-505, 2009.

[12] X.-Z. Li and H. Nikaido, "Efflux-mediated drug resistance in bacteria: an update," Drugs, vol. 69, no. 12, pp. 1555-1623, 2009.

[13] R. W. Bussmann, G. Malca-García, A. Glenn et al., "Minimum inhibitory concentrations of medicinal plants used in Northern Peru as antibacterial remedies," Journal of Ethnopharmacology, vol. 132, no. 1, pp. 101-108, 2010.

[14] F. M. Frey and R. Meyers, "Antibacterial activity of traditional medicinal plants used by Haudenosaunee peoples of New York State," BMC Complementary and Alternative Medicine, vol. 10, article 64, 2010.

[15] P. Kloucek, Z. Polesny, B. Svobodova, E. Vlkova, and L. Kokoska, "Antibacterial screening of some Peruvian medicinal plants used in Callería District," Journal of Ethnopharmacology, vol. 99, no. 2, pp. 309-312, 2005.

[16] T. R. H. Nielsen, V. Kuete, A. K. Jäger, J. J. M. Meyer, and N. Lall, "Antimicrobial activity of selected South African medicinal plants," BMC Complementary \& Alternative Medicine, vol. 12, article 74, 2012.

[17] E. M. Tekwu, A. C. Pieme, and V. P. Beng, "Investigations of antimicrobial activity of some Cameroonian medicinal plant extracts against bacteria and yeast with gastrointestinal relevance," Journal of Ethnopharmacology, vol. 142, no. 1, pp. 265273, 2012.

[18] B. Kaleeswaran, S. Ilavenil, and S. Ravikumar, "Screening of phytochemical properties and antibacterial activity of Cynodon dactylon L," International Journal of Current Research, vol. 3, pp. 83-88, 2010.
[19] A. G. Singh, A. Kumar, and D. D. Tewari, "An ethnobotanical survey of medicinal plants used in Terai forest of western Nepal," Journal of Ethnobiology and Ethnomedicine, vol. 8, article 19, 2012.

[20] T. J. Motley, "The ethnobotany of sweet flag, Acorus calamus (Araceae)," Economic Botany, vol. 48, no. 4, pp. 397-412, 1994.

[21] K. R. Rajbhandari, Ethnobotany of Nepal, Ethnobotanical Society of Nepal, Kathmandu, Nepal, 1st edition, 2001.

[22] N. P. Manandhar, Plants and People of Nepal, Timber Press, Portland, Ore, USA, 2002. 

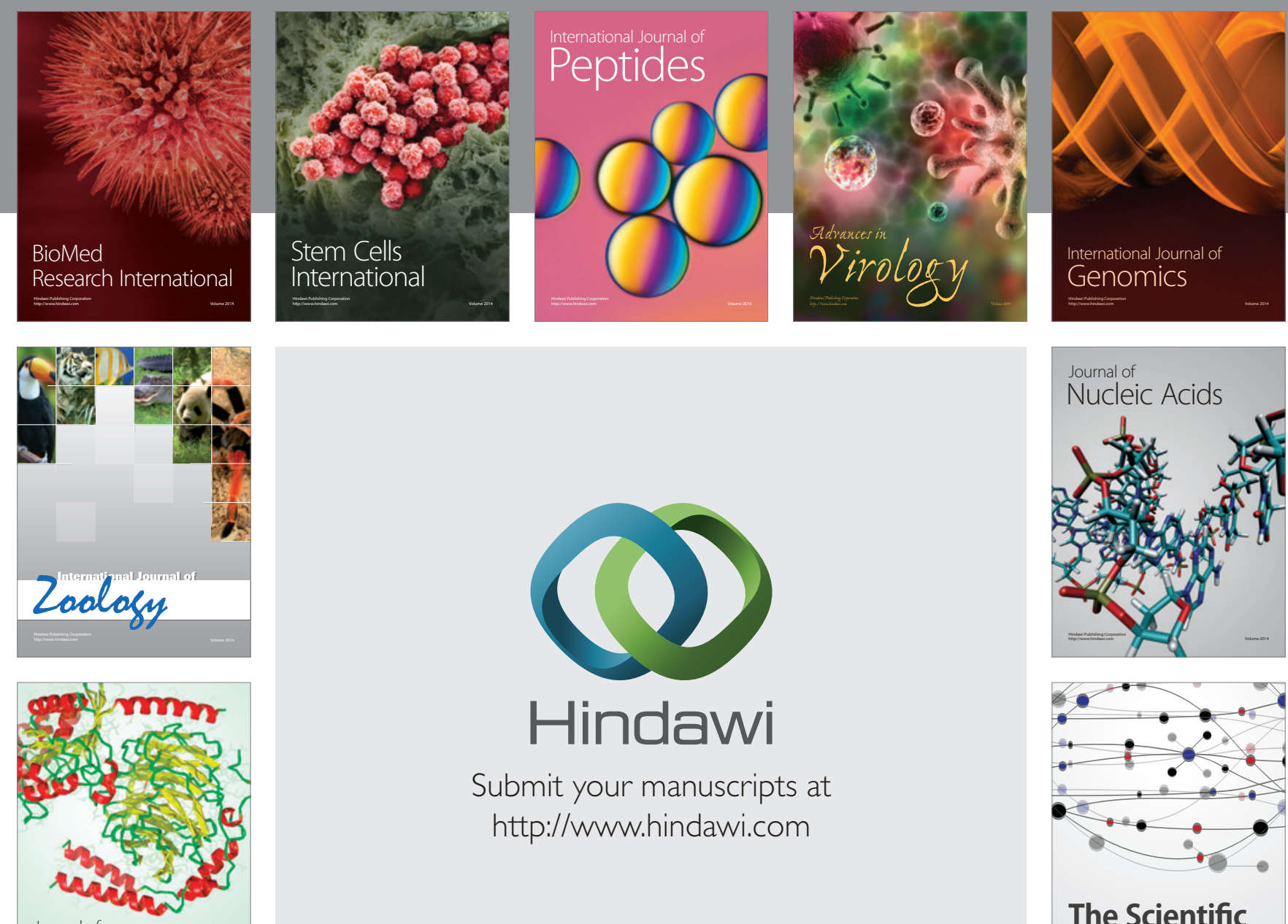

Submit your manuscripts at

http://www.hindawi.com

Journal of
Signal Transduction
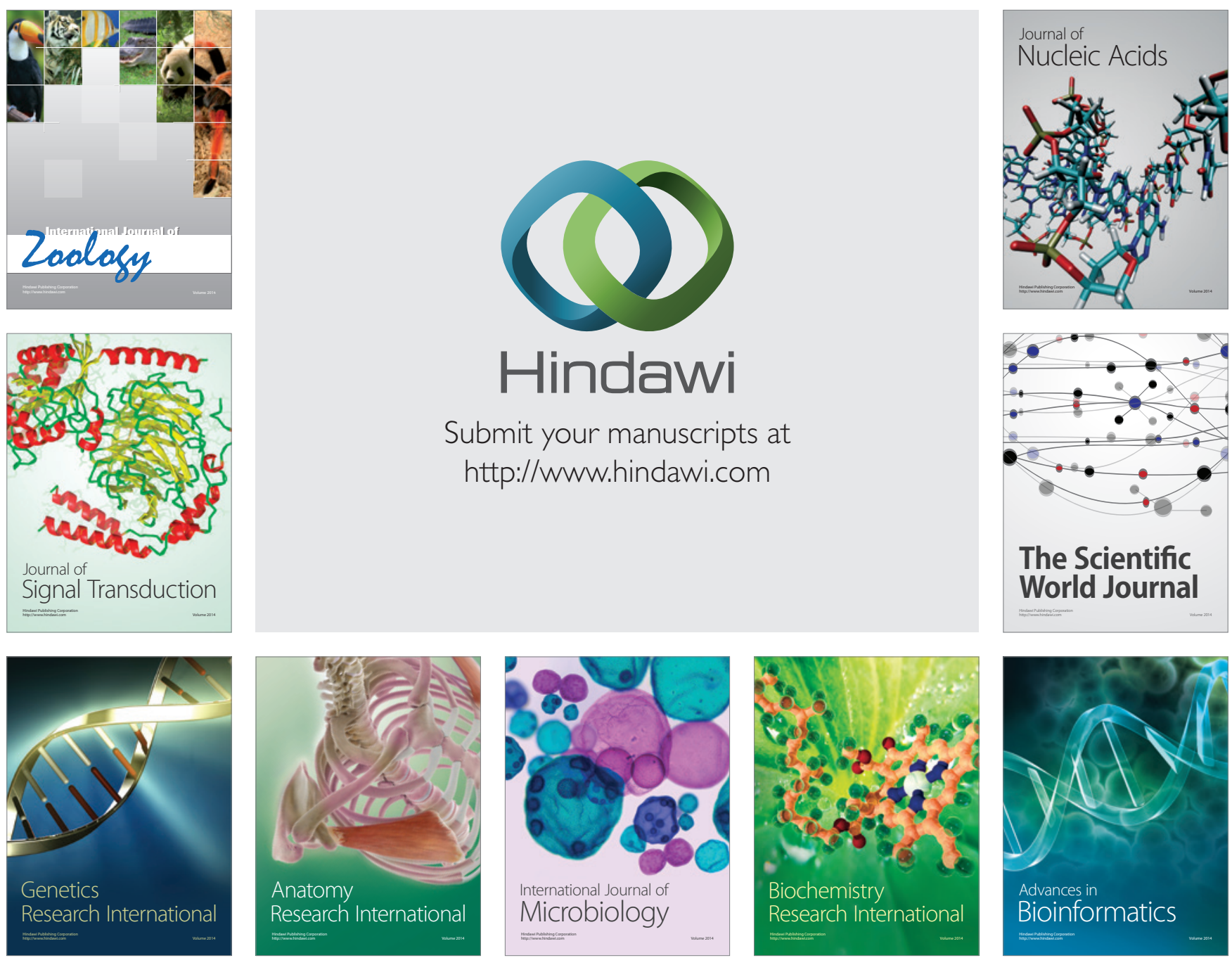

The Scientific World Journal
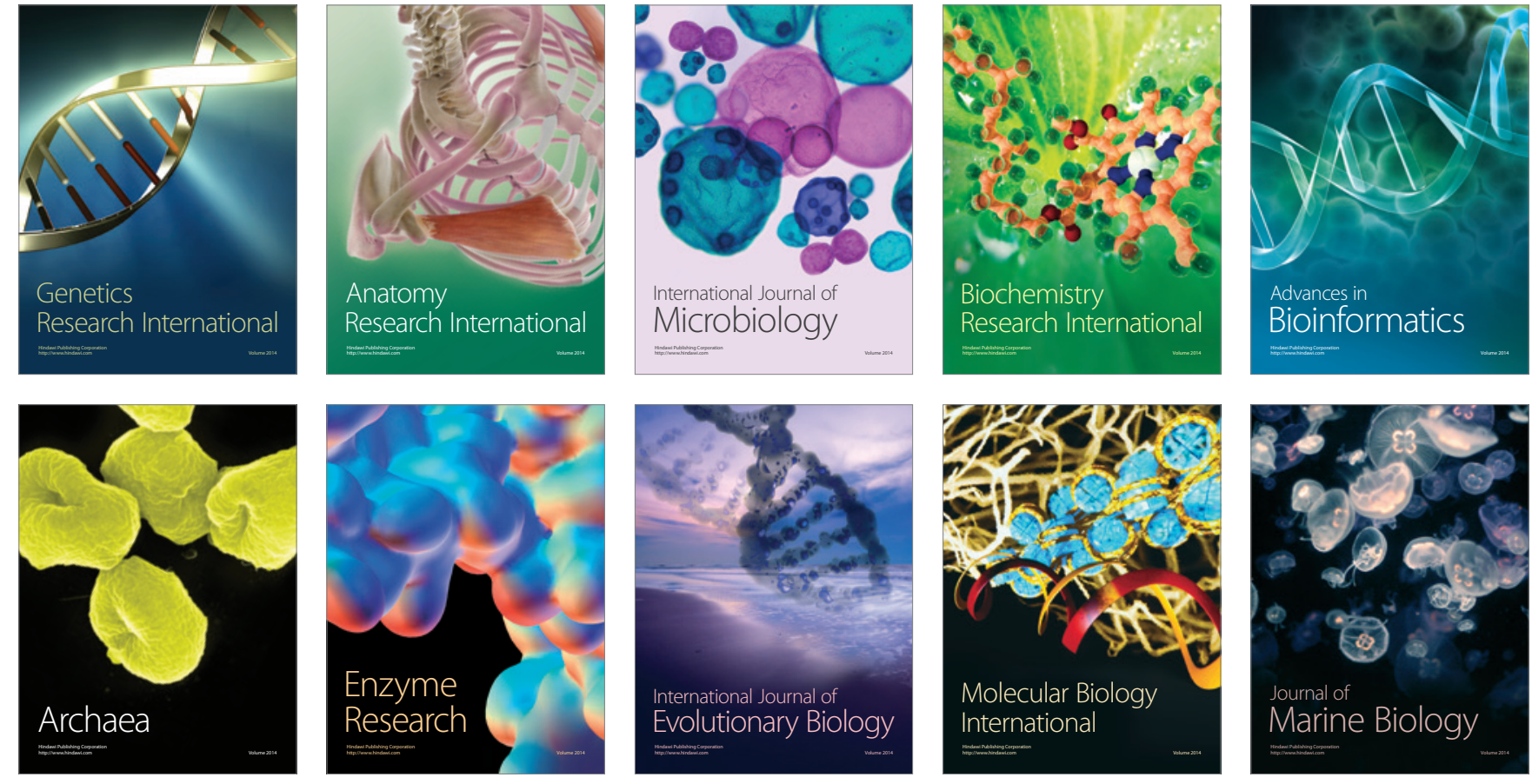